\title{
ENCAPSULATION OF LACTOBACILLUS ACIDOPHILUS IN YEAST CELL WALLS (SACCHAROMYCES CEREVISIAE) FOR IMPROVING SURVIVAL IN GASTROINTESTINAL CONDITIONS
}

\author{
Le Nguyen Han ", Le Huynh Hong Van, Tran Van Duc, Dong Thi Anh Dao \\ Department of Food Technology, Faculty of Chemical Engineering, \\ HCM City University of Technology-Vietnam National University, 268 Ly Thuong Kiet St., \\ Ward 14, Dist. 10, Hochiminh City \\ "Email: lenguyenhan@gmail.com
}

Received: 15 November 2015; Accepted for publication: 31 March 2016

\begin{abstract}
In search of high-quality healthcare products, it is required that probiotic preparations consumed in gastro-intestinal condition remain metabolically active and preserve their activity. Several recent studies, consequently, have focused on probiotic protection via encapsulation in order to optimize probiotics' viability as well as their delivery into gastro-intestinal environment. The objectives of this study were to find out a new material for encapsulation of probiotics, utilizing capsules prepared from $S$. cerevisiae to protect living probiotic cells. The encapsulation of cells was achieved, using the crack scars of the yeast cell walls (YCW) created by the sonication method. Besides, some probiotic cells can be considered as being encapsulated by some surrounded yeast cells by direct cell-cell contact. It is concluded that thanks to encapsulation by yeast cells, probiotic's metabolic activity and survival are markedly improved. This suggests a high potential in protecting probiotics from the extreme condition of digestion process and can be applied in protecting probiotic preparations in food formulations as well. It was found that encapsulation yield in this study reached its highest point at $82.008 \pm 1.123 \%$. Viability of encapsulated probiotic in simulated gastric juice (SGJ) after 150 minutes is $19.048 \pm$ $2.701 \%$, compared to that of free cells at $0 \%$. Likewise, after a 4-hour treatment in simulated intestinal juice (SIJ) $(0.5 \%$ bile salt) encapsulated probiotic proves better survival at $56.338 \pm$ $5.094 \%$ than free cell at $43.677 \pm 2.058 \%$.
\end{abstract}

Keywords: probiotic, encapsulation, Lactobacillus acidophilus, yeast capsules, gastrointestinal conditions, viability.

\section{INTRODUCTION}

Probiotics play a crucial part in improving and maintaining human health. In order to trigger their advantages, probiotics however have to exist in living form to an appropriate extent in preparations and preserve high viability in gastro-intestinal tract. Several studies confirm that 
probiotics should be viable at least $10^{6} \mathrm{CFU} \mathrm{g}{ }^{-1}$ of food product [1] or $10^{7} \mathrm{CFU} \mathrm{\textrm {g } ^ { - 1 }}$ at point of delivery [2]; alternatively, be adequately consumed with the daily amount of $10^{8} \mathrm{CFU} \mathrm{g}^{-1}$ [3]. It is also reported that products with probiotics in free form become little efficient in human body since probiotics mostly die and are unable to activate their effect. The idea of providing probiotics with a biological protective coat against extreme digestive conditions currently receives significant attention from several recent studies $[4,5,6]$. Consequently, they have focused on probiotic protection via encapsulation in order to optimize probiotic's viability as well as their delivery in to gastro-intestinal environment.

The application of microorganism such as yeast cells as capsules for encapsulation of bioactive compounds has been in widespread investigation since the 1970s [7, 8, 9, 10, 11, 12]. Yeast cells then act as containers for compounds that human body is unable to synthesize and the mechanism is to expose yeast cells to liquid hydrophobes. Although encapsulation in YCW has been successfully made to several organic as well as inorganic materials such as medical compounds, oil, vitamins, minerals, etc. [7, 11, 12], little has been mentioned so far regarding encapsulating living cells such as probiotics in YCW. Consequently, this article aims to report a preliminary study into this promising issue.

\section{MATERIALS AND METHODS}

\subsection{Bacterial strain and culture conditions}

L.acidophilus ATCC 43121 (LA) was used in this study. Freeze-dried cells were rehydrated in $5 \mathrm{~mL}$ MRS broth and then incubated in conditions appropriate for their growth $\left(37^{\circ} \mathrm{C}\right.$ in $\left.18 \mathrm{~h}\right)$. After that, cultures were moved into liquid MRS broth and grown in the same condition above

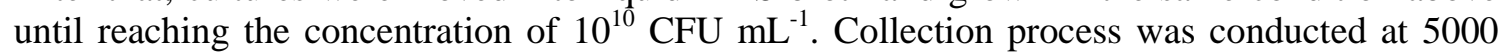
rpm for 5 minutes centrifugation at low temperature $\left(4{ }^{\circ} \mathrm{C}\right)$. Cells collected from MRS broth were washed twice with sterile saline solution. Washed cells then were selected for later experiments and cells concentration was determined by pour plating in MRS agar. Plates were also incubated in the same conditions mentioned above [6].

\subsection{Yeast cell capsules preparation}

In our previous study [13], the optimization of sonication treatment for yeast cell disruption in order to make yeast capsules was discussed. Briefly, the spent yeasts (S. cerevisiae (Meyen ex EC Hansen ATCC 204508)) were collected from experimental brewing factory of HCMC University of Food Industry. This spent yeasts were reused for the purpose of finding a new utilization way for a large amount of spent yeasts from brewery industry in our country. Spent yeasts were washed by repeated centrifugation until the liquid phase in centrifuge tube became purified to remove the beer in spent yeasts.

YCW, after washed by centrifugation method, would be treated with sonication (at the optimal value found in our previous study) at $71 \%$ duty cycle, equivalent to $532.5 \mathrm{~W}$ (Sonicator®; Misonix, USA), in 5.226 minutes in order to disrupt the cell walls. The highest disruption rate recorded was $36.263 \pm 0.884 \%$. Because ultrasound mainly has impact on the bud scars on cell walls, disruption will then make a small hole on cell walls (Fig.1), turning the yeast cells to strong covers to protect probiotics against extreme conditions in digestive environment. 
After sonication treatment, intracellular components of yeast cells were removed by centrifugation. The treated YCW were collected and washed with sterile distilled water at the rate of $3000 \mathrm{rpm}$ several times until the upper layer got clear.

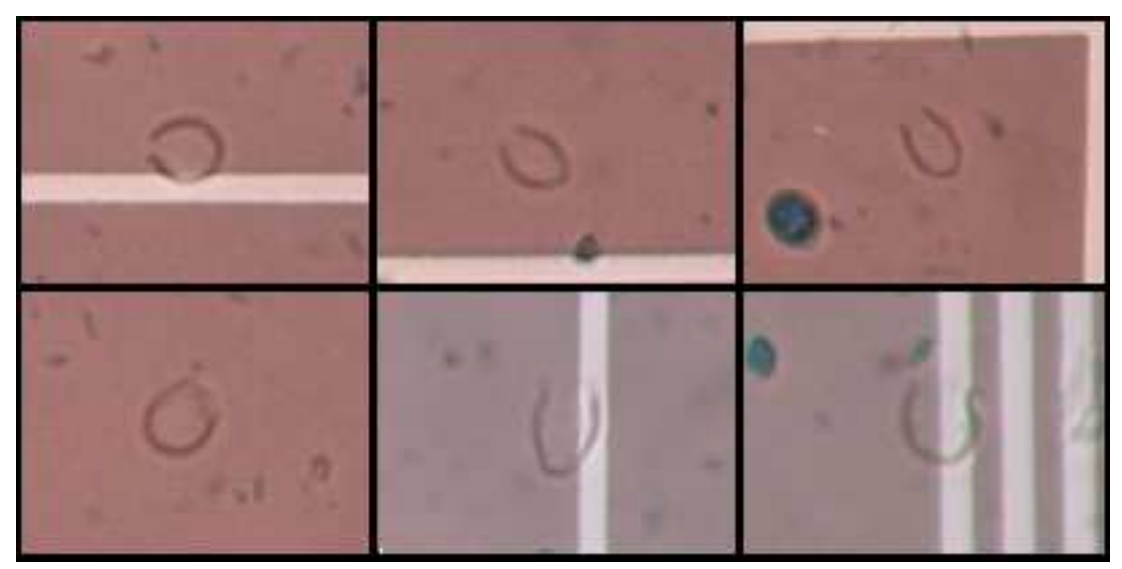

Figure 1. Yeast capsules photographed by digital camera $\mathrm{x} 10$ under objective lens $\mathrm{x} 40$ on hemocytometer. The cells which have been disrupted by sonication and the internal contents were removed out of cell wall by centrifugation. The disrupted YCW as above can be a strong cover for LA.

Subsequently, the collected YCW were added by a small amount of distilled water and the mixture was then poured into a freeze drying flask, made quick freezing at $-45^{\circ} \mathrm{C}$. The freeze sample after that was dried at vacuum pressure $(0.0010 \mathrm{mbar})$ to make water phase transition from solid form to steam. The purpose of this step was to reduce the moisture amount in YCW sample to prolong its quality and make it available as microcapsules for the later experiments of LA encapsulation.

\subsection{Encapsulation procedures}

LA culture was centrifuged as mentioned above to collect cells. Then, collected LA cells were dissolved in physiological saline solution so that cell concentration was $30 \% \mathrm{w} / \mathrm{w}$. This mixture was then added by the dried YCW prepared in the previous stage and shaken on orbital shaker. The shaking step was to make LA evenly disperse in yeast capsule suspension, which then in its turns increased contact rate and encapsulation ability. In this step, the study was conducted on 3 main variables: weight ratio of yeast cell capsules and LA cells $\left(\mathrm{m}_{\mathrm{YCW}}\right.$ : $\left.\mathrm{m}_{\mathrm{LA}}\right)$, shaking time and speed of orbital shaker.

The ratio $\mathrm{m}_{\mathrm{YCw}}$ : $\mathrm{m}_{\mathrm{LA}}$ was prepared at different values $(0.5: 1) ;(1: 1) ;(2: 1) ;(3: 1)$ and treated with shaking step for encapsulation to find out the optimal ratio (with fixed shaking time of 30 minutes and fixed speed of $300 \mathrm{rpm}$ ). Based on the found-out optimal ratio, the effects of the shaking time were examined in range of 10-60 minutes with the 10 minute-jump (with fixed speed of $300 \mathrm{rpm}$ ). Finally, the shaking speed was examined in range of $100-500 \mathrm{rpm}$ with the $100 \mathrm{rpm}$-jump (with the optimal ratio $\mathrm{m}_{\mathrm{YCw}}$ : $\mathrm{m}_{\mathrm{LA}}$ and shaking time found previously).

The glass funnel, filter holders, and filtrate flask were sterilized and assembled with vacuum filtration system. Whatman filter paper (Whatman 7404-004 ALDRICH) made of cellulose nitrate $(\mathrm{D}=47 \mathrm{~mm}$, hole size $=0.45 \mu \mathrm{m})$ was put on the filter holder. The shaken sample was poured into the glass funnel and the vacuum pump was powered to create vacuum pressure. Cell mixture in the glass funnel was then washed several times by saline solution. After 
that, the filter paper was taken out and put into the sterilized test tube. This step was to employ vacuum pressure to enhance the encapsulation rate. As the filter paper holes were smaller than both YCW and LA cells, all were retained.

The cell mixture after first filtration was filtered again by Whatman filter paper (Whatman 7193-004 ALDRICH) $(\mathrm{D}=47 \mathrm{~mm}$, hole size $=3 \mu \mathrm{m})$. Filter paper holes used in this case were smaller than YCW but greater than LA cells. The yeast cells with LA cells encapsulated inside and LA cells in contact with yeast cells by direct cell-cell contact (in other words, LA cells were encapsulated among many yeast cells) would be retained on the filter paper while the nonencapsulated cells would go through it. The filtrate was then centrifuged at $5000 \mathrm{rpm}$ in 15 minutes and weighed to work out the weight of non-encapsulated cells based on which the EY would be calculated. EY was determined by the equation below:

$$
\mathrm{EY}=\frac{\mathrm{M}_{0}-\mathrm{M}}{\mathrm{M}_{0}} \times 100
$$

where EY was the encapsulation yield, expressed in percentage (\%); $\mathrm{M}_{0}$ was the initial weight of LA cells used (g); and M was the weight of free LA cells that collected from the filtrate ( $\mathrm{g}$ ).

\subsection{Simulated gastric juice (SGJ) and Simulated intestinal juice (SIJ) preparation}

SGJ was prepared following method previously used in the study of Michida et al. [14]. Suspending pepsin (P7000, 1:10.000) was dissolved into sterile saline water $(\mathrm{NaCl} 0.5 \% \mathrm{w} / \mathrm{v})$ so that its concentration reached $3 \mathrm{~g} \mathrm{~L}^{-1}$ and adjusted to $\mathrm{pH}=2$ by concentrate $\mathrm{HCl}$ or $\mathrm{NaOH} 0.1$ mol L ${ }^{-1}$. SIJ was prepared by dissolving pancreatin USP (P-1500) into sterile saline water $(\mathrm{NaCl}$ $0.5 \% \mathrm{w} / \mathrm{v}$ ) so that its concentration reached $1 \mathrm{~g} \mathrm{~L}^{-1}$, then adding bile salt (OX-BILE EXTRACT POWDER, Titan Biotech, India) to the concentration of $4.5 \%$ and adjusted $\mathrm{pH}=8$ by $\mathrm{NaOH} 0.1$ mol L $\mathrm{L}^{-1}$.

\subsection{Statistical analysis}

All the experiments were run in triplicates. The results presented in this study were the medium values \pm standard deviation.

The results were tested by ANOVA with the support of Minitab to determine whether the differences among the values were statistically significant $(p<0.05)$.

\section{RESULTS AND DISCUSSION}

\subsection{Effect of the weight ratio of YCW and LA on EY}

Moisture content of YCW capsules and LA cells was determined by moisture analyzer with the values of: $4.8 \pm 0.06 \%$ and $87.4 \pm 0.3 \%$, respectively. Then, the used weight of YCW and LA cells in the experiments was calculated in accordance with the amount of dry matter at different ratios. The determined values were presented in Fig. 2. The ratio $m_{\mathrm{YCW}}: \mathrm{m}_{\mathrm{LA}}$ had statistically impact on EY ( $\left.\mathrm{p}_{\text {value }}<0.05\right)$.

This experiment examined the ratio $\mathrm{m}_{\mathrm{YCW}}: \mathrm{m}_{\mathrm{LA}}$ at the following values $(0.5: 1) ;(1: 1) ;(2: 1)$; (3:1) (with fixed the shaking time of 30 minutes and speed of $300 \mathrm{rpm}$ ). The collected data showed that when amount of YCW was increased, EY reached its peak at 1:1 with $76.374 \pm$ 2.232. However, EY tent to decline when amount of YCW continues at 2:1 and 3:1. This can be 
explained as follows: when amount of yeast cells increases, viscosity of the solution increases accordingly leading to creasing cell stickiness and a decline in cell dipersion in the suspension.

From the collected data, the ratio $\mathrm{m}_{\mathrm{YCW}}: \mathrm{m}_{\mathrm{LA}}$ at $1: 1$ was the optimal value selected for later experiments.

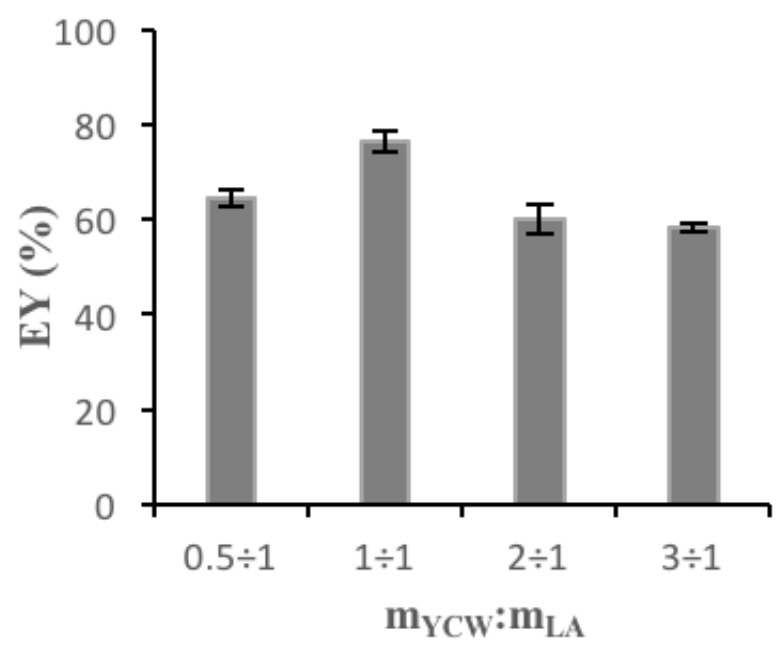

Figure 2. Effect of ration mYCW: mLA on EY. The ratio mYCW: mLA at the following values $(0.5: 1)$; $(1: 1) ;(2: 1) ;(3: 1)$ with fixed the shaking time of 30 minutes and speed of $300 \mathrm{rpm}$. The EY was the mean of three experiments $(n=3)$ with the error bars representing the standard deviation of the mean.

\subsection{Effect of the shaking time on EY}

Figure 3 showed that shaking time had significant impact on EY. As treament time was increased from 10 to 40 minutes (with fixed shaking speed of $300 \mathrm{rpm}$ and ratio $\mathrm{m}_{\mathrm{YCw}}$ : $\mathrm{m}_{\mathrm{LA}}$ at $1: 1)$, EY rose accordingly from $62.763 \pm 0.514 \%$ to $80.441 \pm 1.587 \%$.

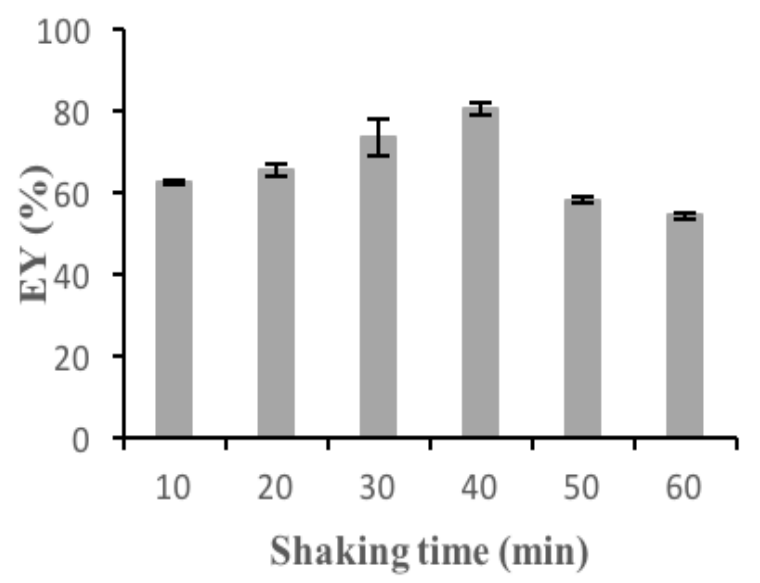

Figure 3. Effect of the shaking time on EY. Treament time was increased from 10 to 40 minutes with fixed shaking speed of $300 \mathrm{rpm}$ and ratio $\mathrm{m}_{\mathrm{YCW}}$ : $\mathrm{m}_{\mathrm{LA}}$ at $1: 1$. The EY was the mean of three experiments $(n=3)$ with the error bars representing the standard deviation of the mean. 
However, after 40 minutes, EY started to decline. Using shaking to encapsulate LA can be considered a dynamic balancing process of moving to and from the disrupted cell walls. A certain amount of LA encapsulated was also probably impacted by strong shakes, falling off and returning to the solution. Based on the time examination results, it was determined that 40 minutes was the optimal period for maximizing balancing and was selected for later experiments.

\subsection{Effect of the shaking speed on EY}

Based on the value previously worked out, this experiment employed the ratio $\mathrm{m}_{\mathrm{YCW}}$ : $\mathrm{m}_{\mathrm{LA}}$ at 1:1 and shaking time of 40 minutes to determine the opitmal shaking speed whose results were presented in Fig. 4.

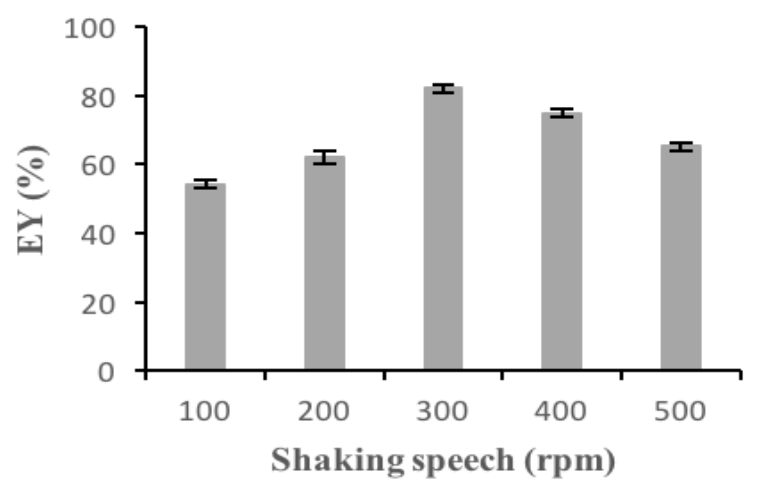

Figure 4. Effect of shaking speed on EY. Shaking speed was increased from $100 \mathrm{rpm}$ to $500 \mathrm{rpm}$ and this experiment employed the ratio $\mathrm{m}_{\mathrm{YCw}}$ : $\mathrm{m}_{\mathrm{LA}}$ at $1: 1$ and shaking time of 40 minutes. The $\mathrm{EY}$ was the mean of three experiments $(\mathrm{n}=3)$ with the error bars representing the standard deviation of the mean.

Obviously, EY was also significantly influenced by shaking speed. Shaking at $100 \mathrm{rpm}$ resulted in poor EY due to its slow speed, which mean suspension stirring was not strong enough to cause high interaction between YCW capsules and LA cells. As shaking speed was increased, interation rose due to stronger stirring making EY higher. However, shaking at 400-500 rpm was too much, causing encapsualted LA to fall off; consequently EY became lower than at $300 \mathrm{rpm}$.

So far, it has been determined that the ratio $\mathrm{m}_{\mathrm{YCW}}$ : $\mathrm{m}_{\mathrm{LA}}=1: 1$, shaking time and speed of 40 minutes and $300 \mathrm{rpm}$ respectively, EY of $82.008 \pm 1.123 \%$ were maximum values for this study. Under the microscope observation, the YCW capsules with LA cells encapsulated inside are shown in Fig. 5.

There have been different reports on EY, greatly depending on varying microorganisms examined, encapsulating techniques and wall material chosen. For instance, Clarice G. et al. [15] used inotropic gelation from pectin as wall material, reaching a similar EY $(84.35 \pm 0.60 \%)$. Corbo et al. [4] reported EY at $\sim 50 \%$ with inotropic gelation and alginate for encapsulation of L.rhamnosus. Similarly, Chávarri et al. [5] got EY ranging from 19.5 to $40.2 \%$ for L.gasseri and B.bifidum, using chitosan coating. Picot et al. [16] who employed spray drying in an attempt to encapsulate B.breve and B.longum reported EY greatly varying 0.03-25.67\%. The possible account for such reported lower EYs is that viability of probiotic is greatly affected by extreme temperature in spray drying. Meanwhile, our study recorded higher EY at $82.008 \pm 1.123 \%$ 
compared to the initial amount of microorganism due to the milder conditions where encapsulation was conducted at $25^{\circ} \mathrm{C}$ and neutral $\mathrm{pH}$.

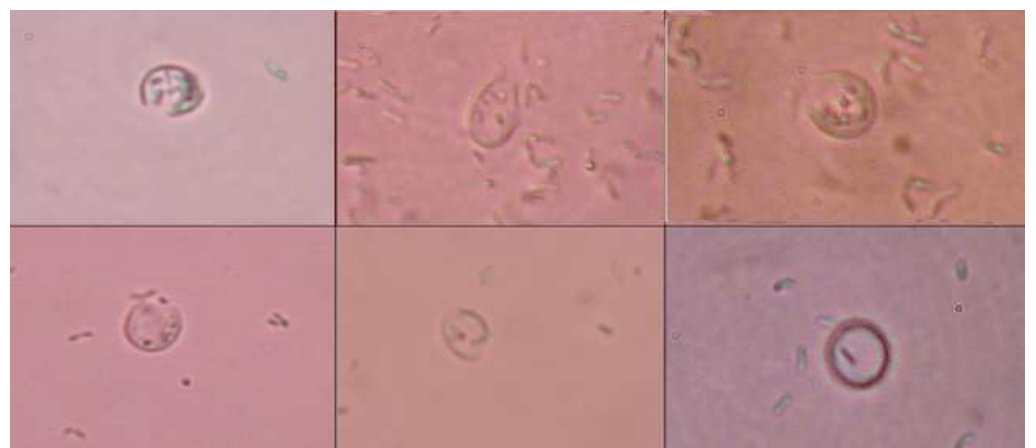

Figure 5. LA cells were encapsulated in yeast cell capsules. A number of LA cells were encapsulated inside the YCW. YCW worked as a protective layer for probiotics, minimizing interaction between LA cells and gastric juice, and increasing its survival.

\subsection{Viability of free and encapsulated LA in SGJ}

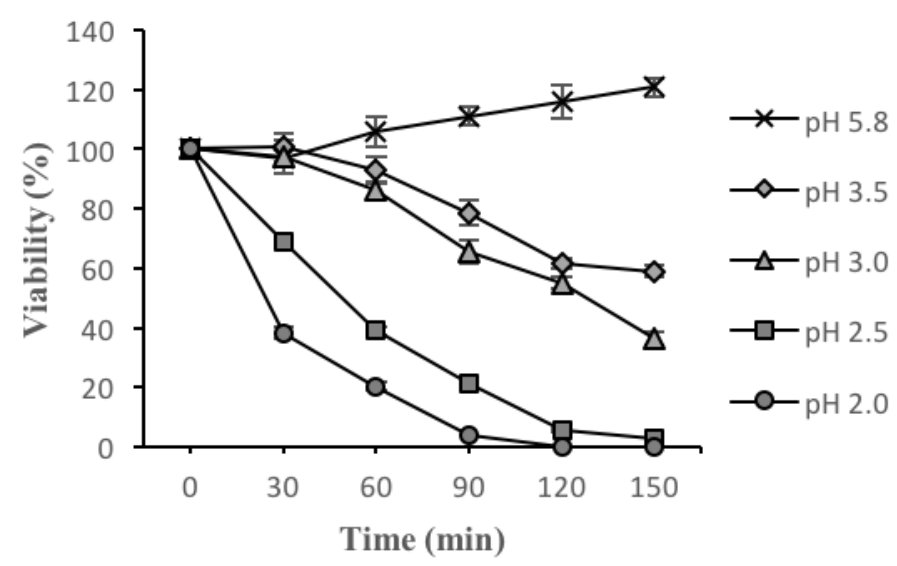

Figure 6. Survival of free LA in SGJ at varied $\mathrm{pH}$ values in 150 minutes. Cell counts are the mean of three experiments $(n=3)$ with the error bars representing the standard deviation of the mean.

Most of the current probiotics preparations are taken in via digestion. With 2 liters of gastric juice daily released and very low $\mathrm{pH}$, humans' stomach forms a barrier that kills most probiotics. Fig. 6 showed that SGJ pH 2 and $\mathrm{pH} 2.5$ eliminated mostly free LA and so did SGJ $\mathrm{pH} 3.0$ and $\mathrm{pH} 3.5$ though less seriously. As for controlled $\mathrm{pH}$, cell viability tent to increase due to substrate-rich medium and appropriate-for-growing $\mathrm{pH}(\mathrm{pH}=5.8)$, consequently cell survival significantly rose after 150 minutes. According to Fig. 6 and Fig.7, free cells increased to $20.7 \%$ compared with $8.1 \%$ of encapsulated cells at this $\mathrm{pH}$ value. As free cells had more interaction with substrate while encapsulated cells in YCW have less, viability of encapsulated cells did increase but not much compared to free cells.

In SGJ pH 2 (Fig. 6), free cells with initial viability of $100 \%$, after 30 and 60 minutes of treatment, had lower survival of $38.322 \pm 1.745 \%$ and $20.408 \pm 1.483 \%$ respectively. With 90 minute treatment, this figure plummeted at only $3.968 \pm 0.196 \%$. This result was quite 
congruent with those presented by Ashraf et al. [17] as they asserted that SGJ pH 2 is screening value for probiotic characteristic of Lactobacillus since on this condition, L.acidophilus, L.delbrucekii, L.rhamnosus show a sharp decrease in cell viability from 90 minutes.

Survival of free LA in pH 2.5 after 150 minutes declined at $2.721 \pm 0.589 \%$. Applying treatment of 120 and 150 minutes, most cells died with viability of $0 \%$ due to low $\mathrm{pH}$ medium, causing intracellular $\mathrm{pH}$ to decrease accordingly and so did the difference in $\mathrm{pH}$ inside probiotic cell walls. This result lead to the fact that probiotic cells could not synthesize ATP due to electrochemical gradient loss. In addition, acidification inside cells reduced activities of several enzymes sensitive to acid, causing confusion in biosynthesis of DNA and protein. Also, according to Presser et al. [18], the presence of several non-crossed-linked anion of organic acids could cause random contact among several particles occurring inside cells, significantly impacting cells' bio-physical activities.

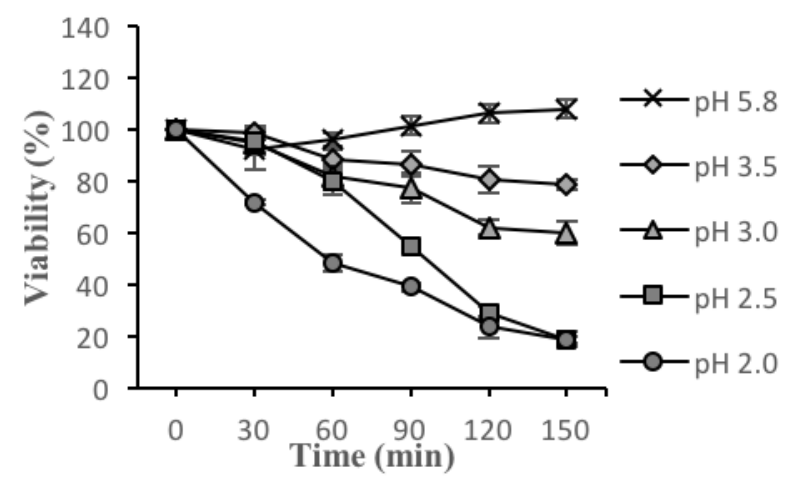

Figure 7. Survival of encapsulated LA in SGJ at varied pH values in 150 minutes. Cell counts were the mean of three experiment $(n=3)$ with the error bars representing the standard deviation of the mean.

With regard to LA encapsulated in YCW, its survival at $\mathrm{pH} 2 \& \mathrm{pH} 2.5$ was considerably improved. Treatment of 120 minutes and $\mathrm{pH} 2$ also proved itself where most free LA could not survive while viability of encapsulated cells reached $23.809 \pm 4.145 \%$ and this figure was $19.048 \pm 2.701 \%$ for treatment of 150 minutes as indicated in Fig.7. It was YCW that worked as a protective layer for probiotics, minimizing interaction between LA and gastric juice, and increasing its survival even on very low $\mathrm{pH}$ condition.

The YCW brings about desired results in improving probiotic viability. In a study where alginate-prebiotic was used to encapsulate LA [19], the concentration of living cells after 180 minute treatment in SGJ is $4.35 \times 10^{11}$ versus $5.59 \times 10^{12}$ initial concentration, equivalent to 7.78 $\%$. Sultana et al. [20] also used calcium alginate combined with Hi-maize starch prebiotic, and the results indicate a marked fall in LA viability though. In milk-based medium at $\mathrm{pH} 4.0$ and 3.0 for 3-hour treatment, the decrease was about $2 \log$ cycles while the loss was $5 \log$ of CFU g ${ }^{-1}$ at $\mathrm{pH} 2.0$.

\subsection{Viability of free and encapsulated LA in SIJ}

In addition to low $\mathrm{pH}$, bile salt in small intestines is another challenge to probiotic survival. Bile salt produced in liver joins in digestive process in that it hydrolyses and absorbs fat as well as plays a significant role in preventing the existence of harmful intestinal microorganism [21]. 
However, Fig. 8 and Fig. 9 indicate that survival of free and encapsulated LA was not much influenced. In fact, this probiotic could resist to bile salt concentration of $0.3 \% ; 0.4 \%$ and $0.5 \%$.

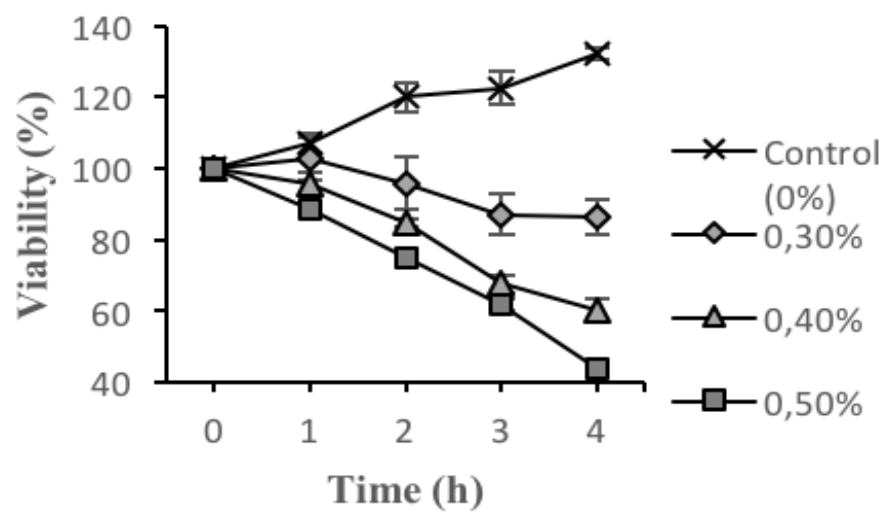

Figure 8. Viability of free LA at various concentration of bile salt in 4 hours. Cell counts were the mean of three experiment $(n=3)$ with the error bars representing the standard deviation of the mean.

In controlled experiment (without bile salt added to MRS broth), viability of cells tent to increase due to substrate-rich environment; in fact, cell survival rises after 4 hour treatment. According to Fig. 8 and Fig. 9, free cells increased to $32.2 \%$ compared to $25.3 \%$ of encapsulated ones. Free cells had more interaction with substrate for living activities and cell proliferation; in contrast, encapsulated cells lied in YCW with less interaction with substrate, so their survival did increase but not significantly compared to free cells.

With bile salt concentration of $0.3 \%$ and 4-hour treatment, viability of free cells was $86.607 \pm 4.971 \%$, indicating a slight (but not significant) decreased as shown in Fig. 8. This proved that LA was bile-resistant at $0.3 \%$ [22]. LA produced hydrolysis enzymes most of which were intracellular ones, acting as a catalyst in the process of hydrolyzing amide linkages between steroid and amino acid chain to support cells' bile-resistance [23]. With bile salt concentration of $0.4 \%$ and $0.5 \%$, cell survival reduced remarkably to $60.471 \pm 3.279 \%$ and $43.677 \pm 2.058 \%$, respectively. This was due to that fact that bile salt of high concentration $(0.4$ $\%$ \& $0.5 \%$ ) blocked several mechanisms inside cells such as causing gene stress, which then affected bio-synthesis of cell walls or DNA repair [16].

As for LA encapsulated in YCW, cell survival at bile concentration of $0.3 \%$ after 4-hour treatment was $90.548 \pm 2.251 \%$. With higher bile salt concentration of $0.4 \%$ and $0.5 \%$, also after 4-hour treatment, cell survival was $68.883 \pm 3.598 \%$ and $56.338 \pm 5.094 \%$, higher than that of free cells at $60.471 \pm 3.279 \%$ and $43.677 \pm 2.058 \%$, respectively. It was YCW that formed a protective layer covering probiotic cells, minimizing LA interaction with bile salt.

Through the collected empirical figures, it suggests that YCW is a potential material for improving viability of probiotic. With its cell wall thickness of $100-200 \mathrm{~nm}$, the cell's structural constituents are mainly made of glucans and mannans with a minor percentage of chitin, and a great amount of proteins entrapped inside. Taken together, these form firm capsules which are completely workable for LAB protection against the severe conditions in digestion [24]. 


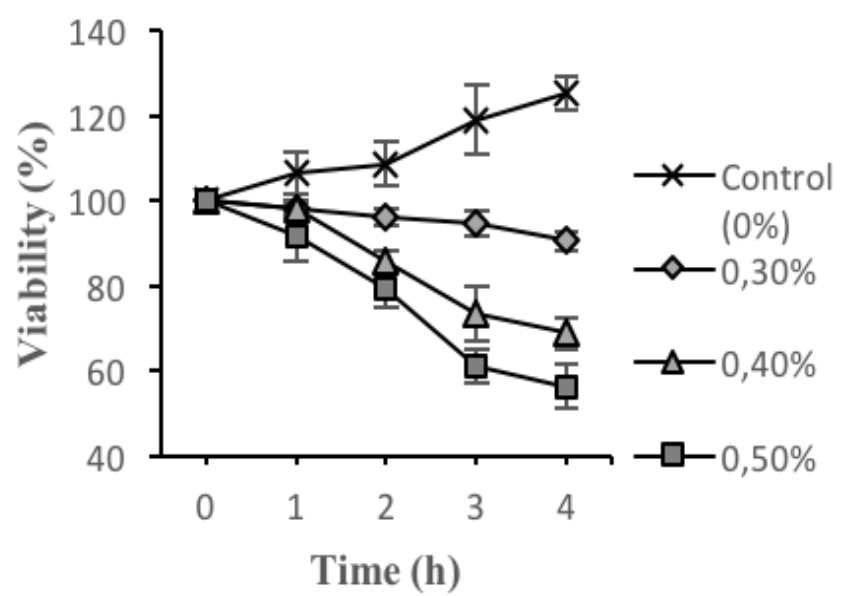

Figure 9. Viability of encapsulated LA at various concentration of bile salt in 4 hours. Cell counts were the mean of three experiment $(n=3)$ with the error bars representing the standard deviation of the mean.

YCW improves LA viability not only since it works as a protective layer between LA and gastric juice but also between yeast and LA cells forms direct cell-cell contact co-aggregation mediated by yeast cell surface and/or cell wall components or metabolites. Phebe et al. [25] pointed out that in $\mathrm{pH}=2.5$ after $8 \mathrm{~h}$ treatment with the mixture of L.rhamnosus HN001 and S.cerevisiae EC-1118, the amount of living cells of L. Rhamnosus is $7.28 \pm 0.31 \mathrm{Log}_{\mathrm{CFU} \mathrm{mL}}{ }^{-1}$ while this figure for mere L.Rhamnosus is $3.26 \pm 0.25$ in comparison with the initial amount of cells at $8.45 \pm 0.07 \mathrm{Log} C F U \mathrm{~mL}^{-1}$. Some relevant studies also proved that protective effect is created by mixed-species biofilms. A typical of this is one conducted by Xie et al. [26] which suggested that in the concentration range of 3.0-5.0 $\log \mathrm{CFU} \mathrm{mL} \mathrm{m}^{-1}$, both viable and lethal yeast significantly improves survival of L.paracasei in SGJ. The effect of mixed-species biofilms is also indicated in the study of van der Veen et al. [27]. The two species of Listeria monocytogenes and L.plantarum also show enhanced resistance to benzalk-onium chloride and peracetic acid thanks to this biofilm.

The mortality rate of free probiotic with the absence of yeast cells in the previous studies and free LA in ours indicates the significant role of yeast cells. Based on those presented above, LA cells in our study have 2 different protective mechanisms. LA cells encapsulated inside YCW are protected by the thick cell walls while some cells are also preserved by the surrounding yeast cells due to the formation of mixed-species biofilms.

\section{CONCLUDING REMARKS}

From the results presented above, this study concludes that YCW is a feasible mean for improving probiotic's tolerance in high acid environment that may be a utility mean in delivery of probiotic into human digestion. This study has determined the parameters for encapsulation method with the following ratio $\mathrm{m}_{\mathrm{YCW}}: \mathrm{m}_{\mathrm{LA}}=1: 1$, shaking time and speed of 40 minutes and 300 rpm respectively. With the EY of $82.008 \pm 1.123 \%$, viability of encapsulated cells reached $19.048 \pm 2.701 \%$ while most free ones could not survive for treatment of SGJ pH 2 in 150 minutes. Encapsulated LA were also improved with better survival at $56.338 \pm 5.094 \%$ than free ones at $43.677 \pm 2.058 \%$ after a 4-hour treatment in SIJ $0.5 \%$ bile salt. This technique has been still under examination so far, but initial results show that $\mathrm{YCW}$ is a new promising material for improving probiotic's viability. 
Acknowledgement. We would like to appreciate Mr. Nguyen Thai Son, HCMC University of Law and Mr. Nguyen Quang Phong, Nguyen-Tat-Thanh University for their comments and technical contribution. Also, our thanks go to colleagues at HCMC University of Technology for their support while this research was in progress.

\section{REFERENCES}

1. Ouwehand C., Salminem S.J. - The health effects of cultured milk products with viable and non-viable bacteria, Int. Dairy J. 8 (2009) 749-758.

2. Lee Y.K., Salminen S. - The coming to age of probiotics, Trends Food Sci. Technol. 6 (1995) 241-245.

3. Lopez-Rubio A., Gavara R., Lagaron J.M. - Bioactive packaging: turning foods into healthier foods through biomaterials, Trends Food Sci. Technol. 17 (2006) 567-575.

4. Corbo M.R., Bevilacqua A., Sinigaglia M. - Shelf life of alginate beads containing lactobacilli and bifidobacteria: Characterization of microspheres containing Lactobacillus delbrueckii subsp. Bulgaricus, Int. J. Food Sci. Tech. 46 (2011) 2212-2217.

5. Chávarri M., Marañón I., Ares R., Ibáñez F.C., Marzo F., Villarán M.C. Microencapsulation of a probiotic and prebiotic in alginate-chitosan capsules improves survival in simulated gastro-intestinal conditions, Int. J. Food Microbiol. 142 (2010) 185189.

6. María C., Izaskun M. - Microencapsulation of a probiotic and prebiotic in alginatechitosan capsules improves survival in simulated gastrointestinal conditions, Int. J. Food Microbiol. 142 (2010) 185-189.

7. Shank J.L. - Encapsulating eg dyes, drugs, chemicals, adhesives...using microorganisms eg fungi, yeasts by forming large fat globules within cell wall, Patent US498208-B (1977).

8. Guorong S., Liqun R., Huazhong Y., Hua X., Guoping P., Sang L., Chen Y. - Yeast cell based micro-encapsulation of chlorogenic acid as a water-soluble antioxidant, J. Food Eng. 80 (2006) 1060-1067.

9. Bishop J.R.P, Nelson G., Lamb J. - Microencapsulation in yeast cells, J. Microencapsul. 15 (1998) 761-773.

10. Roshanak S., Omid R., Zahra K., Mohsen F., BiBi S.F.B. - Characterization of Encapsulated Berberine in Yeast Cells of Saccharomyces cerevisiae, Iran J. Pharm. Res. 14 (2015) 1-19.

11. Nelson, Duckham, Crothers - Microencapsulation in yeast cells and applications in drug delivery, A.C.S. symposium series Polymeric Drug Delivery I: Particulate Drug Carriers. (2006) 268-281.

12. Paramera E.I., Konteles S.J., Karathanos V.T. - Microencapsulation of curcumin in cells of Saccharomyces cerevisiae, Food Chem. 125 (2011) 892-902.

13. Le Nguyen Han, Le Huynh Hong Van, Tran Van Duc, Dong Thi Anh Dao - Optimizing yeast cell (Saccharomyces cerevisiae) disruption by sonication treatment. Int. J. Eng. Tech. Res. 3(4) (2015) 281-286. 
14. Michida H., Tamalampudi S., Pandiella S., Webb C., Fukuda H., Kondo A. - Effect of cereal extracts and cereal fiber on viability of L.plantarum under gastrointestinal tract conditions, Biochem. Eng. J. 28(1) (2006) 73-78.

15. Clarice G., Karina S.C., Maria C.R., Flavia N.S., Carlos R.F.G, Mirna L.G. - Viability of Lactobacillus acidophilus La5 in pectin-whey protein microparticles during exposure to simulated gastrointestinal conditions, Food Res. Int. 51 (2013) 872-878.

16. Picot A., Lacroix C. - Encapsulation of bifidobacteria in whey protein-based microcapsules and survival in simulated gastrointestinal conditions and in yoghurt, Int. Dairy J. 14 (2004) 505-515.

17. Ashraf M., Arshad M., Siddique M., Muhammad G. - In vitro screening of locally isolated Lactobacillus species for probiotic properties, Pak. Vet. J. 29(4) (2009) 186-190.

18. Presser K.A., Ratkowsky D.A., Ross T. - Modeling the growth rate of Escherichia coli as a function of $\mathrm{pH}$ and lactic acid concentration, Appl. Environ. Microbiol. 63 (1997) 23552360 .

19. Filomena N., Florinda F., Raffaele C., Alfonso S., Pier-angelo O. - Fermentative ability of alginate-prebiotic encapsulated Lactobacillus acidophilus and survival under simulated gastrointestinal conditions, J. Funct. Foods 1 (2009) 319 - 323.

20. Sultana K., Godward G., Reynolds N., Arumugaswamy R., Peiris P., Kailasapathy K. Encapsulation of probiotic bacteria with alginate-starch and evaluation of survival in simulated gastrointestinal conditions and in yoghurt, Int. J. Food Microbiol. 62 (2000) $47-$ 55.

21. Gilliland S.E., Nelson C.R., Maxwell C. - Assimilation of Cholesterol by Lactobacillus acidophilus, Appl. Environ. Microbiol. 49 (1985) 377-381.

22. Fellows P., Food processing technology: Principles and Practice, CFC Press, Boca Raton, USA (2000).

23. Begley M., Gahan C.G.M., Hill C. - The interaction between bacteria and bile, FEMS Microbiol. Rev. 29 (2005) 625-651.

24. Kapteyn J.C., Van D.E.H., Klis F.M. - The contribution of cell wall proteins to the organization of the yeast cell wall, Biochim. Biophys. Acta 1426 (2) (1999) 373-383.

25. Phebe L.L., Mingzhan T., Shao Q.L. - Saccharomyces cerevisiae EC-1118 enhances the survivability of probiotic Lactobacillus rhamnosus HN001, Appl. Microbiol. Biotechnol. 99 (16) (2015) 6803-11.

26. Xie N., Zhou T., Li B. - Kefir yeasts enhance probiotic potentials of Lactobacillus paracase $i \mathrm{H} 9$ : The positive effects of co-aggregation between the two strains, Food Res. Int. 45 (1) (2012) 394-401.

27. van der Veen S., Abee T. - Mixed species biofilms of Listeria monocytogenes and Lactobacillus plantarum show enhanced resistance to benzalkonium chloride and peracetic acid., Int. J. Food Microbiol. 144 (3) (2011) 421-431. 